BMJ Open

Diabetes

Research

\& Care

\title{
Superior socioeconomic status in patients with type 2 diabetes having gastric bypass surgery: a case-control analysis of 10642 individuals
}

\author{
Magnus Sundbom (D) , ${ }^{1}$ Stefan Franzén, ${ }^{2}$ Johan Ottosson, ${ }^{3}$ Ann-Marie Svensson ${ }^{4}$
}

\begin{abstract}
To cite: Sundbom M, Franzén S, Ottosson J, et al. Superior socioeconomic status in patients with type 2 diabetes having gastric bypass surgery: a case-control analysis of 10642 individuals. BMJ Open Diab Res Care 2020;8:e000989. doi:10.1136/ bmjdrc-2019-000989
\end{abstract}

Received 17 October 2019 Revised 21 December 2019 Accepted 9 January 2020

(D) Check for updates

(C) Author(s) (or their employer(s)) 2020. Re-use permitted under CC BY-NC. No commercial re-use. See rights and permissions. Published by BMJ.

${ }^{1}$ Surgical Sciences, Uppsala University, Uppsala, Sweden ${ }^{2}$ National Diabetes Register, Centre of Registers, Gothenburg, Sweden ${ }^{3}$ Department of Surgery, Faculty of Medicine and Health, Örebro University, Örebro, Sweden ${ }^{4}$ Centre of Registers in Region Västra Götaland, Gothenburg, Sweden

Correspondence to Dr Magnus Sundbom; magnus.sundbom@surgsci. uu.se

\section{ABSTRACT}

Introduction The incidence of type 2 diabetes mellitus (T2DM) is increasing, in parallel with the epidemic of obesity. Although bariatric surgery, which profoundly affects T2DM, has increased 10-fold since the millennium, only a fraction of diabetics is offered this treatment option. Objective To investigate the association between clinical and socioeconomic factors in selecting patients with T2DM for bariatric surgery in a publicly financed healthcare system.

Research design and methods Cohort study using prospectively registered data from two nationwide quality registers, the Scandinavian Obesity Surgery Registry (SOReg) and the Swedish National Diabetes Register (NDR), and data from two government agencies. An age, gender and body mass index-matched case-control analysis containing 10642 patients with T2DM was performed. Results Patients with T2DM having bariatric surgery had a higher education level (upper secondary school or college level, OR $1.42 \%$ and $95 \% \mathrm{Cl}$ (1.29 to 1.57) and 1.33 (1.18 to 1.51 ), respectively) as well as a higher income (OR 1.37 (1.22 to 1.53 ) to 1.94 (1.72 to 2.18) for quartile 2-4) than non-operated patients. Operated patients were more often married or had been married (OR 1.51 (1.37 to 1.66) and 1.65 (1.46 to 1.86$)$, respectively) as well as natives ( $O R$ 0.84 ( 0.73 to 0.95 ) if born in the rest of Europe). Groups did not differ regarding relevant laboratory data and present medication, nor in former in-patient diagnoses. Conclusion Despite similar clinical data, superior socioeconomic status was associated with increased rate of bariatric surgery in patients with T2DM. We believe that this warrants actions, for example concerning referral patterns.

\section{INTRODUCTION}

The incidence of type 2 diabetes mellitus (T2DM) is increasing, in parallel with the epidemic of obesity. ${ }^{12}$ Accordingly, bariatric surgery has increased 10-fold since the millennium $^{34}$ and in 2016, almost 700000 bariatric procedures were done worldwide. ${ }^{3}$ Although obesity ${ }^{5}$ and the need for bariatric surgery is more prevalent in lower socioeconomic groups, ${ }^{6}$ the impact of socioeconomic status on selecting individuals with T2DM for bariatric surgery has not been studied.

\section{Significance of this study}

What is already known about this subject?

- Although bariatric surgery profoundly affects type 2 diabetes mellitus, only a fraction of diabetics are offered surgical treatment.

What are the new findings?

- Despite similar clinical data, superior socioeconomic status was associated with increased rate of bariatric surgery.

How might these results change the focus of research or clinical practice?

- Indications for referring patients to bariatric surgery should be discussed and revised.

\section{Bariatric surgery in diabetes}

Bariatric surgery profoundly affects T2DM and is better than all other treatment modalities as demonstrated in several randomized clinical trials. ${ }^{7-11}$ In a recent 5-year follow-up by our group, two-thirds of all patients were still off all their former antidiabetic drugs. ${ }^{12}$ At the same time point, the risk of microvascular complications was found to be $47 \%$ lower in 1111 patients with treated with bariatric surgery compared with a matched non-operated cohort. Moreover, a large decrease in the risk of diabetic retinopathy $(48 \%)$ and diabetic kidney disease $(46 \%)$ was found in this Danish study. ${ }^{13}$ According to the latest recommendation from the American Diabetes Association, patients with T2DM and body mass index (BMI) over 35, in whom conservative weight management has failed, should be recommended surgery. Furthermore, metabolic surgery (performed by identical methods to bariatric surgery) could be considered in patients with T2DM with BMI between 30 and 35 who do not achieve durable weight loss and improvement in comorbidities with reasonable non-surgical methods. ${ }^{14}$ Despite this, only a fraction of patients with 
T2DM are offered bariatric surgery, for example, $0.07 \%$ of 277862 patients in the multicenter Diabetes Prospective Follow-up Initiative (DPV database) from Germany and Austria. ${ }^{15}$ In the DPV database, bariatric patients were predominantly female, younger and had a longer diabetes duration as well as a higher BMI compared with non-operated patients. Socioeconomic factors were however not studied.

\section{Swedish healthcare system}

Sweden has a tax-financed healthcare system that aims to give equal healthcare to all citizens. Bariatric surgery with internationally accepted indications ${ }^{16}$ is fully covered within this system, that is, physicians at all levels of the healthcare system are free to refer patients with BMI $>35$ for surgical evaluation. In Sweden, all healthcare contacts are registered on the patient's unique personal identification number, which is also used in quality registries and other governmental databases. The present register-based cohort study of routine clinical practice was based on patients included in the national quality registers for bariatric surgery, the Scandinavian Obesity Surgery Registry (SOReg) ${ }^{17}$ and diabetes, the Swedish National Diabetes Register (NDR) ${ }^{18}$ Since 2007, SOReg has contained $>70000$ patients who have had a bariatric procedure, mainly primary gastric bypass (GBP). At baseline, $15 \%$ of all included patients had T2DM. Coverage has been proven high in SOReg when validated to the Swedish National Patient Registry. ${ }^{19}$ In 2016, NDR contained data on almost 400000 unique patients, and when compared with the Swedish Prescribed Drug Register, a 93\% conformity regarding patients with T2DM treated with medications for diabetes was seen. ${ }^{20}$

The aim of the present study was to evaluate which types of patients with T2DM had been selected for primary gastric bypass by comparing socioeconomic variables as well as relevant clinical data and former in-hospital diagnoses.

\section{MATERIAL AND METHODS}

After merging SOReg and NDR data, we identified 5321 patients with T2DM who had had a primary GBP between 1 January 2007 and 31 December 2015. Operated patients were matched 1:1 on age, gender and BMI to non-operated patients from the NDR. The Longitudinal Database for Health Insurance and Labor Market studies $^{21}$ provided information about socioeconomic variables; level of education was divided in elementary school (9 years), upper secondary school (10-12 years) and college level ( $>12$ years), while registered income was separated in quartiles $(\mathrm{q} 1-\mathrm{q} 4)$. Marital status was divided into single, married, divorced and widowed. Country of birth was determined as Sweden, Europe (except Sweden) and the rest of the world. Patient-specific data (BMI, smoking, hemoglobin A1c, creatinine, glomerular filtration rate, blood pressure and relevant ongoing medication) from the year of surgery were collected from the two quality registers, SOReg and NDR. Likewise, in-hospital care, based on principal International Classification of Diseases-10 diagnoses from the National Patient Register during 1997-2015 was compared. Data on controls were retrieved similarly and variables were set by the same calendar year as their operated counterparts.

\section{Statistical methods}

The study has a case-control design where each case, that is, a person who underwent a gastric bypass was fitted with an untreated person matched on age, gender, BMI and calendar time. The matched data set was then analyzed using a logistic regression model evaluating the association between being treated with gastric bypass and socioeconomic status by estimated OR and 95\% CIs. The analysis model contained main effects for the four matching variables in addition to income, level of education and marital status at the time of surgery and country of origin. Descriptive statistics are presented in averages and SEs for continuous variables, and counts and proportions for categorical variables. All statistical tests use $\mathrm{p}<0.05$ as significance level and a standardized difference, difference in proportions divided by $\mathrm{SE},>20$ was considered to be an imbalance (small effect size). The analysis was done using SAS V.9.4.

\section{RESULTS}

In total, we identified 10642 individuals with T2DM (average age $=48$ years, average BMI $=41 \mathrm{~kg} / \mathrm{m}^{2}$ and $60 \%$ females) and as demonstrated in table 1, the groups differed slightly in age and BMI (standardized difference 12.2 and 11.7, respectively).

\section{Adjusted model}

In the adjusted model, the group having had gastric bypass was associated with higher education (upper secondary school or college level, OR 1.42 (95\% CI 1.29 to 1.57 ) and 1.33 (1.18 to 1.51 ), respectively) as well as a higher income (OR 1.37 (1.22 to 1.53) to 1.94 (1.72 to 2.18) for q2-q4 compared with non-operated patients. Operated patients were more often married or had been

Table 1 Patient characteristics of the 10642 included patients in the case-control analysis

\begin{tabular}{cccc}
\hline Variable & $\begin{array}{l}\text { Gastric bypass } \\
(\mathbf{n = 5 3 2 1 )}\end{array}$ & $\begin{array}{l}\text { Controls } \\
(\mathbf{n = 5 3 2 1 )}\end{array}$ & $\begin{array}{l}\text { Standardized } \\
\text { difference (\%) }\end{array}$ \\
\hline $\begin{array}{c}\text { Gender } \\
\text { Male }\end{array}$ & $2098(39.4 \%)$ & $1926(36.2 \%)$ & 0.0 \\
$\begin{array}{c}\text { Female } \\
\text { Age }\end{array}$ & $3223(60.6 \%)$ & $3395(63.8 \%)$ & 0.0 \\
$\begin{array}{c}\text { Years } \\
\text { BMl }\end{array}$ & $49.0(9.5)$ & $47.1(11.5)$ & 12.2 \\
\hline $\mathrm{kg} / \mathrm{m}^{2}$ & $42.0(5.7)$ & $40.9(7.3)$ & 11.7 \\
\hline
\end{tabular}

Standardized difference, ie, difference in proportions divided by SE; imbalance defined as absolute value $>20$ (small effect size). 
Table 2 Case-control analysis of the association between socioeconomic variables and gastric bypass surgery

\begin{tabular}{|c|c|c|}
\hline Variable & OR with $95 \% \mathrm{Cl}$ & $P$ value \\
\hline \multicolumn{3}{|l|}{ Education } \\
\hline Elementary school & Ref & $<0.001$ \\
\hline Upper secondary school & 1.33 (1.18 to 1.51$)$ & \\
\hline College level & $1.42(1.29$ to 1.57$)$ & \\
\hline \multicolumn{3}{|l|}{ Income } \\
\hline Quartile 1 & $1.00(1.00$ to 1.00$)$ & $<0.001$ \\
\hline Quartile 2 & 1.37 (1.22 to 1.53$)$ & \\
\hline Quartile 3 & 1.76 (1.57 to 1.97$)$ & \\
\hline Quartile 4 & 1.94 (1.72 to 2.18$)$ & \\
\hline \multicolumn{3}{|l|}{ Marital status } \\
\hline Single & Ref & $<0.001$ \\
\hline Married & 1.51 (1.37 to 1.66$)$ & \\
\hline Divorced & 1.65 (1.46 to 1.86$)$ & \\
\hline Widowed & 0.88 (0.67 to 1.15$)$ & \\
\hline \multicolumn{3}{|l|}{ Country of birth } \\
\hline Sweden & Ref & 0.007 \\
\hline Europe (except Sweden) & 0.84 (0.73 to 0.95$)$ & \\
\hline Rest of the world & 0.87 (0.77 to 1.00$)$ & \\
\hline
\end{tabular}

Statistical differences within groups were tested by a logistic regression model.

married (OR 1.51 (1.37 to 1.66 ) and 1.65 (1.46 to 1.86), respectively) as well as natives (OR 0.84 (0.73 to 0.95 ) if born in the rest of Europe) (table 2).

As demonstrated in table 3, no differences were seen in laboratory values, present medication and former principal inpatient care diagnoses with potential medical relevance in selecting individuals for a bariatric procedure (all standardized differences well below 10).

\section{DISCUSSION}

Using nationwide registers, we found that bariatric surgery was more common in patients with T2DM having superior socioeconomic status, that is, higher education and income, married or having been married and natives. Because clinical data did not differ, we believe that this warrants actions, for example, concerning indications for referrals to bariatric surgery.

\section{Education and income}

In line with the present study, Memarian et al showed that bariatric surgery in Sweden from 1990 to 2010 was most frequent in individuals with $>11$ years of education. ${ }^{22}$ Likewise, during 2011-2012 in Australia, individuals with severe obesity in the two most disadvantaged socioeconomic quintiles were $40 \%$ less likely to receive bariatric surgery. ${ }^{23}$ Moreover, in a recent American publication on self-management education for diabetics $(\mathrm{n}=84179)$, individuals with low education level (high school level or less) received less education (OR 0.71 (95\% CI 0.66 to
$0.78)$ ) than college graduates. ${ }^{24}$ In the present study, operated patients had higher income than the non-operated individuals. This is in line with the study by Wallace et $a l$, who showed in 2010, that lower income was associated with lower OR for bariatric surgery in a cohort of 774000 American patients with morbid obesity from the 2006 National Inpatient Sample. ${ }^{25}$ The same was true for 87749 patients in the same registry who had had bariatric surgery, when compared with $>22$ million eligible individuals from the 2005 to 2006 National Health and Nutrition Examination Survey. ${ }^{6}$ Moreover, the eligible individuals with obesity had lower income than non-eligible individuals, that is, normal-weight citizens.

\section{Marital status}

In the above-mentioned publication on sociodemographic factors associated with diabetes self-management education, no difference was found between married, widowed/divorced/separated and never married individuals. ${ }^{24}$ In the literature, being married, perhaps as a proxy for social support, is associated with increased adherence to the postoperative outpatient programme ${ }^{26}$ and almost seven times increased odds of having superior medium-term weight loss in 250 consecutive patients undergoing bariatric surgery. ${ }^{27}$ On the other hand, an increased change in marital status, both divorces and marriages, after bariatric surgery has been found in Sweden compared with the general population. ${ }^{28} \mathrm{We}$ believe that this reflects the fundamental changes in life and social situation that occur after bariatric surgery for many patients.

\section{Country of birth}

Native Swedes with T2DM were operated more often than immigrants in our study. Likewise, the largest difference in incidence rate between Swedes and immigrants having bariatric surgery overall in 2001-2011 was observed in low-income individuals (3.4 and 2.3 per 100000 individuals, respectively).$^{29}$ Because few studies have focused on the selection of individuals for bariatric surgery in first-generation or second-generation immigrants, we searched the literature for differences in race. In the USA, African-Americans were less likely to have been recommended bariatric surgery by their doctors when seen at four diverse primary care practices in Greater Boston. ${ }^{30}$ When using population-based data from Michigan, a summary measure of race, gender and socioeconomic status from the 2000 census resulted in an inverse linear relationship to rates of bariatric surgery. ${ }^{5}$ Although race and ethnicity were not independently associated with likelihood of proceeding with bariatric surgery in a cohort of 651 patients at two academic centers in the USA ${ }^{31}$ we believe that the influence of socioeconomical factors should be minimized in modern healthcare.

\section{Possible explanations}

The main question about why patients with superior socioeconomical status had bariatric surgery more often 
Table 3 Comparison of clinical data, laboratory values and medication and principal in-hospital diagnoses with potential relevance in selecting individuals for a bariatric procedure

\begin{tabular}{|c|c|c|c|}
\hline & $\begin{array}{l}\text { Gastric bypass } \\
(n=5321)\end{array}$ & $\begin{array}{l}\text { Controls } \\
(n=5321)\end{array}$ & Standardized difference (\%) \\
\hline Smoking (yes) & $576(15.9 \%)$ & $942(19.7 \%)$ & 0.1 \\
\hline \multicolumn{4}{|l|}{ Laboratory values, average (SD) } \\
\hline Hemoglobin A1c $(\mathrm{mmol} / \mathrm{mol})$ & $59.9(16.9)$ & $58.5(16.9)$ & 5.9 \\
\hline Creatinine (mmol/L) & $68.1(27.6)$ & $68.0(25.4)$ & 0.3 \\
\hline Glomerular filtration rate $(\mathrm{mL} / \mathrm{min})$ & $97.2(25.0)$ & $98.3(27.5)$ & 2.8 \\
\hline Systolic blood pressure $(\mathrm{mm} \mathrm{Hg})$ & $132.8(14.5)$ & $132.5(15.6)$ & 1.3 \\
\hline Diastolic blood pressure $(\mathrm{mm} \mathrm{Hg})$ & $80.3(9.6)$ & $80.0(9.8)$ & 2.1 \\
\hline \multicolumn{4}{|l|}{ Medication, n (\%) } \\
\hline Metformin & $3947(74.2 \%)$ & $3769(70.8 \%)$ & 0.1 \\
\hline Sulfonylureas & $627(11.8 \%)$ & $541(10.2 \%)$ & 0.0 \\
\hline DPP-4 inhibitors & $257(4.8 \%)$ & $239(4.5 \%)$ & 0.0 \\
\hline Glitazones & $190(3.6 \%)$ & $150(2.8 \%)$ & 0.0 \\
\hline GLP-1 agonists & $310(5.8 \%)$ & $245(4.6 \%)$ & 0.0 \\
\hline Insulin & 1967 (37.0\%) & $1886(35.4 \%)$ & 0.0 \\
\hline NSAID & $1852(34.8 \%)$ & $1476(27.7 \%)$ & 0.1 \\
\hline Opiates & $1658(31.2 \%)$ & $1026(19.3 \%)$ & 0.2 \\
\hline Antihypertensives & $2504(66.2 \%)$ & $3034(60.4 \%)$ & 0.1 \\
\hline Lipid-lowering drugs & $2688(50.5 \%)$ & $2414(45.4 \%)$ & 0.1 \\
\hline Anticoagulants & $153(2.9 \%)$ & $170(3.2 \%)$ & 0.0 \\
\hline Psychiatric drugs & $520(9.8 \%)$ & $529(9.9 \%)$ & 0.0 \\
\hline Drugs for alcohol abuse & $94(1.8 \%)$ & $122(2.3 \%)$ & 0.0 \\
\hline \multicolumn{4}{|l|}{ Principal in-hospital care, $\mathbf{n}(\%)$} \\
\hline Coronary heart disease & $408(7.7 \%)$ & $313(5.9 \%)$ & 0.0 \\
\hline Acute myocardial infarction & $174(3.3 \%)$ & $169(3.2 \%)$ & 0.0 \\
\hline Stroke & $109(2.1 \%)$ & $103(1.9 \%)$ & 0.0 \\
\hline Atrial fibrillation & $165(3.1 \%)$ & $149(2.8 \%)$ & 0.0 \\
\hline Heart failure & $153(2.9 \%)$ & $168(3.2 \%)$ & 0.0 \\
\hline Hypoglycemia with coma & $57(1.1 \%)$ & $61(1.1 \%)$ & 0.0 \\
\hline Hyperglycemia & $83(1.6 \%)$ & $130(2.4 \%)$ & 0.0 \\
\hline Kidney failure & $60(1.1 \%)$ & $82(1.5 \%)$ & 0.0 \\
\hline Cancer & $113(2.1 \%)$ & $158(3.0 \%)$ & 0.0 \\
\hline Psychiatric disorders & $361(6.8 \%)$ & $346(6.5 \%)$ & 0.0 \\
\hline Alcohol abuse & $94(1.8 \%)$ & $122(2.3 \%)$ & 0.0 \\
\hline Deep vein/pulmonary thrombosis & $74(1.4 \%)$ & $65(1.2 \%)$ & 0.0 \\
\hline Abdominal pain & $387(7.3 \%)$ & $334(6.3 \%)$ & 0.0 \\
\hline Ulcer and/or reflux & $107(2.1 \%)$ & $72(1.3 \%)$ & 0.0 \\
\hline Gallstone, gallbladder disease & $428(8.0 \%)$ & $366(6.9 \%)$ & 0.0 \\
\hline Malnutrition & $22(0.4 \%)$ & $41(0.8 \%)$ & 0.0 \\
\hline
\end{tabular}

Standardized difference, ie, difference in proportions divided by SE; imbalance defined as absolute value $>20$ (small effect size). DPP-4, dipeptidyl peptidase 4; GLP-1, glucagon-like peptide 1; NSAID, non-steroidal anti-inflammatory drug.

remains. More privileged patients are perhaps more persuasive because they have increased information on alternative treatments as well as striving more for improved quality of life. In a recent systematic review of
28 qualitative studies with 580 participants, many participants believed that weight loss surgery would produce positive psychological impacts by strengthening their personal identities, their relationships and improving 
their engagement in public and professional life. ${ }^{32}$ Thus, patients seek an improvement in social life to a large extent. In contrast, individuals with lower socioeconomic status might be more grateful for the given treatment in primary care and believe that it is enough. Moreover, patient selection is questionable not only in bariatric surgery. In malignant diseases, low socioeconomic status is associated with inferior prognosis in lung cancer ${ }^{33}$ as well as oropharyngeal ${ }^{34}$ and esophageal cancer ${ }^{35}$ and a doubled risk of having late-stage breast cancer, ${ }^{36}$ among other inferiorities. This is probably due to a combination of patients' and doctors' delay. Finally, socioeconomic differences in use of bariatric surgery may also reflect patient's perception about surgery as well, particularly in a publicly funded healthcare system such as the present.

\section{Strengths and limitations}

There are several strengths of the study; above all the almost complete, national coverage of patients diagnosed with T2DM, with measured BMI and the possibility to use inpatient registries to identify all hospitalizations. Moreover, the use of the Swedish public healthcare system omitted the influence of insurance companies and other economic factors to a large extent. The bariatric procedure GBP was chosen because it dominated in Sweden during the study period. ${ }^{17}$ Furthermore, a recent study showed that patients selected to GBP most often met international criteria for having bariatric surgery and the weight result was more similar between hospitals. ${ }^{37}$ GBP is also known to be effective in achieving diabetes resolution, for example, $77 \%$ vs $60 \%$ after sleeve gastrectomy. ${ }^{38}$ However, in certain populations, such as the Indian, sleeve gastrectomy could be superior. ${ }^{39}$ The fact that only primary bariatric procedures were studied creates a homogenous cohort but excludes information on the selection of patients having a second bariatric procedure (revisional cases); however, these only represent $4.4 \%$ of all cases in SOReg. ${ }^{17}$ Compared with the remaining patients registered in SOReg, individuals with diabetes were older ( 48.6 vs 40.0 years on average, $\mathrm{p}<0.001$ ) and had a slightly higher average BMI (42.0 vs $41.7, \mathrm{p}<0.01)$, whereas no difference in gender or year of surgery was seen. ${ }^{17}$ Finally, the present results concerning marriage status must be interpreted with caution because cohabitation is common in Sweden and we only had information on legal marriages. Moreover, the matching on age, gender, BMI and year of surgery precluded us from studying any differences between the groups for these four variables.

\section{CONCLUSION}

Despite the intention to provide equal healthcare in Sweden, socioeconomic factors such as education, income, marital status and country of birth varied between patients with T2DM having had bariatric surgery or not. This warrants action because surgery was more common in patients considered to have superior socioeconomic status. Initially, national and local indications for referring patients to bariatric surgery should be discussed and revised.

Contributors MS, SF, J0 and A-MS contributed to the conception and design of the study, the acquisition and interpretation of data. SF contributed to the analysis of data. MS, J0 and A-MS drafted the work and revised it critically for important intellectual content. All authors approved the final version to be published; agree to be accountable for all aspects of the work in ensuring that questions related to the accuracy or integrity of any part of the work are appropriately investigated and resolved.

Funding The authors have not declared a specific grant for this research from any funding agency in the public, commercial or not-for-profit sectors.

Competing interests None declared.

\section{Patient consent for publication Not required.}

Ethics approval The study was approved by the Regional Ethical and Review Board of the University of Gothenburg, Sweden.

Provenance and peer review Not commissioned; externally peer reviewed.

Data availability statement All data relevant to the study are included in the article. No additional data available.

Open access This is an open access article distributed in accordance with the Creative Commons Attribution Non Commercial (CC BY-NC 4.0) license, which permits others to distribute, remix, adapt, build upon this work non-commercially, and license their derivative works on different terms, provided the original work is properly cited, appropriate credit is given, any changes made indicated, and the use is non-commercial. See: http://creativecommons.org/licenses/by-nc/4.0/.

ORCID iD

Magnus Sundbom http://orcid.org/0000-0002-6243-2859

\section{REFERENCES}

1 Ingelfinger JR, Jarcho JA. Increase in the incidence of diabetes and its implications. N Engl J Med 2017;376:1473-4.

2 World Health Organisation. Obesity: preventing and managing the global epidemic. Report of a who consultation. World Health Organ Tech Rep Ser 2000;894:1-253.

3 Angrisani L, Santonicola A, lovino P, et al. IFSO worldwide survey 2016: primary, endoluminal, and revisional procedures. Obes Surg 2018;28:3783-94.

4 Buchwald H, Williams SE. Bariatric surgery worldwide 2003. Obes Surg 2004;14:1157-64.

5 Birkmeyer NJO, Gu N. Race, socioeconomic status, and the use of bariatric surgery in Michigan. Obes Surg 2012;22:259-65.

6 Martin M, Beekley A, Kjorstad R, et al. Socioeconomic disparities in eligibility and access to bariatric surgery: a national populationbased analysis. Surgery for Obesity and Related Diseases 2010;6:8-15.

7 Schauer PR, Kashyap SR, Wolski K, et al. Bariatric surgery versus intensive medical therapy in obese patients with diabetes. $N$ Engl $J$ Med 2012;366:1567-76.

8 Schauer PR, Bhatt DL, Kirwan JP, et al. Bariatric surgery versus intensive medical therapy for diabetes -5 -year outcomes. $N$ Engl $J$ Med 2017;376:641-51.

9 Mingrone G, Panunzi S, De Gaetano A, et al. Bariatric surgery versus conventional medical therapy for type 2 diabetes. N Engl J Med 2012;366:1577-85

10 Mingrone G, Panunzi S, De Gaetano A, et al. Bariatric-metabolic surgery versus conventional medical treatment in obese patients with type 2 diabetes: 5 year follow-up of an open-label, singlecentre, randomised controlled trial. The Lancet 2015;386:964-73.

11 Ikramuddin S, Korner J, Lee W-J, et al. Roux-En-Y gastric bypass vs intensive medical management for the control of type 2 diabetes, hypertension, and hyperlipidemia: the diabetes surgery study randomized clinical trial. JAMA 2013;309:2240-9.

12 Sundbom M, Hedberg J, Marsk R, et al. Substantial decrease in comorbidity 5 years after gastric bypass: a population-based study from the Scandinavian obesity surgery registry. Ann Surg 2017;265:1166-71.

13 Madsen LR, Baggesen LM, Richelsen B, et al. Effect of Roux-en-Y gastric bypass surgery on diabetes remission and complications in individuals with type 2 diabetes: a Danish population-based matched cohort study. Diabetologia 2019;62:611-20. 
14 American Diabetes Association. Standards of Medical Care in Diabetes-2019 Abridged for Primary Care Providers. Clin Diabetes 2019;37:11-34.

15 Laubner K, Prinz N, Brückel J, et al. Comparative characteristics of patients with type 2 diabetes mellitus treated by bariatric surgery versus medical treatment: a multicentre analysis of 277,862 patients from the German/Austrian DPV database. Obes Surg 2018;28:3366-73.

16 International Federation for the Surgery of Obesity. Statement on patient selection for bariatric surgery. Obes Surg 1997;7:41.

17 Scandinavian Obesity Surgery Registry (SOReg). Homepage in English, 2018

18 The Swedish National Diabetes Register (NDR). Homepage in English, 2019.

19 Tao W, Holmberg D, Näslund E, et al. Validation of obesity surgery data in the Swedish national patient registry and Scandinavian obesity registry (SOReg). Obes Surg 2016;26:1750-6.

20 The Swedish National Diabetes Register (NDR). Årsrapport 2017, 2017.

21 Ludvigsson JF, Svedberg P, Olén O, et al. The longitudinal integrated database for health insurance and labour market studies (LISA) and its use in medical research. Eur J Epidemiol 2019;34:423-37.

22 Memarian E, Calling S, Sundquist K, et al. Sociodemographic differences and time trends of bariatric surgery in Sweden 19902010. Obes Surg 2014;24:2109-16.

23 Keating C, Backholer K, Moodie M, et al. Differences in the rates of treatment of severe obesity using bariatric surgery across socioeconomic groups. JAMA Surg 2015;150:367-8.

24 Adjei Boakye E, Varble A, Rojek R, et al. Sociodemographic factors associated with engagement in diabetes self-management education among people with diabetes in the United States. Public Health Rep 2018;133:685-91.

25 Wallace AE, Young-Xu Y, Hartley D, et al. Racial, socioeconomic, and Rural-Urban disparities in obesity-related bariatric surgery. Obes Surg 2010;20:1354-60.

26 Wheeler E, Prettyman A, Lenhard MJ, et al. Adherence to outpatient program postoperative appointments after bariatric surgery. Surg Obes Relat Dis 2008;4:515-20.

27 Wedin S, Madan A, Correll J, et al. Emotional eating, marital status and history of physical abuse predict 2-year weight loss in weight loss surgery patients. Eat Behav 2014;15:619-24.
28 Bruze G, Holmin TE, Peltonen M, et al. Associations of bariatric surgery with changes in interpersonal relationship status: results from 2 Swedish cohort studies. JAMA Surg 2018;153:654-61.

29 Memarian E, Sundquist K, Calling S, et al. Country of origin and bariatric surgery in Sweden during 2001-2010. Surg Obes Relat Dis 2015;11:1332-41.

30 Wee CC, Davis RB, Chiodi S, et al. Sex, race, and the adverse effects of social stigma vs. other quality of life factors among primary care patients with moderate to severe obesity. J Gen Intern Med 2015;30:229-35.

31 Stanford FC, Jones DB, Schneider BE, et al. Patient race and the likelihood of undergoing bariatric surgery among patients seeking surgery. Surg Endosc 2015;29:2794-9.

32 Cohn I, Raman J, Sui Z. Patient motivations and expectations prior to bariatric surgery: a qualitative systematic review. Obes Rev 2019;20:1608-18.

33 Torre LA, Siegel RL, Jemal A, et al. Lung cancer statistics. Adv Exp Med Biol 2016;893:1-19.

34 Megwalu UC. Impact of County-Level socioeconomic status on oropharyngeal cancer survival in the United States. Otolaryngol Head Neck Surg 2017;156:665-70.

35 Linder G, Sandin F, Johansson J, et al. Patient education-level affects treatment allocation and prognosis in esophageal- and gastroesophageal junctional cancer in Sweden. Cancer Epidemiol 2018;52:91-8.

36 Orsini M, Trétarre B, Daurès J-P, et al. Individual socioeconomic status and breast cancer diagnostic stages: a French case-control study. Eur J Public Health 2016;26:445-50.

37 Poelemeijer YQM, Liem RSL, Våge V, et al. Gastric bypass versus sleeve gastrectomy: patient selection and short-term outcome of 47,101 primary operations from the Swedish, Norwegian, and Dutch national quality registries. Ann Surg 2019. doi:10.1097/ SLA.0000000000003279. [Epub ahead of print: 20 Mar 2019].

38 Panunzi S, De Gaetano A, Carnicelli A, et al. Predictors of remission of diabetes mellitus in severely obese individuals undergoing bariatric surgery: do BMl or procedure choice matter? A metaanalysis. Ann Surg 2015;261:459-67.

39 Bhasker AG, Dixon JB, Lakdawala M. Selection of bypass vs sleeve for the management of type-2 diabetes in severely obese: could ethnicity play a role? Obes Surg 2018;28:3073-9. 